\title{
INVERSÃO DA POSSE: INTERFACE ENTRE LÍNGUA E DISCURSO NO PORTUGUÊS BRASILEIRO
}

\author{
Inversion of Possession: Inversión de Propiedad: \\ Interfaces between Language and Interfaz entre Lengua y Discurso \\ Discourse in Brazilian Portuguese en Portugués Brasileño
}

\author{
João Kogawa* \\ Indaiá de Santana Bassani** \\ Universidade Federal de São Paulo \\ Escola de Filosofia, Letras e Ciências Humanas - Departamento de Letras \\ Guarulhos, SP, Brasil
}

\begin{abstract}
Resumo: Este artigo investiga, por meio de uma interface entre morfossintaxe e análise do discurso, a inversão das relações de posse em construções do tipo 'sou seu x', em que x é substituído por uma função social de parentesco ou proximidade. Os dados analisados foram coletados a partir de uma metodologia específica em site de busca com vistas a observar a ocorrência de seis construções em contexto de uso (i) 'sou seu marido'; (ii) ‘sou sua mulher'; (iii) ‘sou seu pai'; (iv) ‘sou sua mãe'; (v) ‘sou seu amigo'; (vi) ‘sou sua amiga'. Nesse tipo de construção, a interpretação de posse, não raro, funciona de modo invertido. Com efeito, o termo nominal possuído, em nível morfossintático, torna-se termo possuidor no discurso, especialmente em dizeres autoritários.
\end{abstract}

Palavras-chave: Discurso. Morfossintaxe. Relação de posse. Dizer autoritário.

\begin{abstract}
This paper investigates the inversion of the relation of possession in constructions of the type "Sou seu x" ('I am your x')", in which x is replaced by a social function of kinship or proximity through an interface between morphosyntax and discourse analysis. Data under investigation were collected from a specific methodology on a web search site aiming at observing the occurrence of six constructions in context of usage (i) "Sou seu marido" ('I am your husband'); (ii) "Sou sua mulher" ('I am your wife'); (iii) "Sou seu pai" ('I am your father'); (iv) "Sou sua mãe" ('I am your mother'); (v) "Sou seu amigo" ('I am your (male) friend'; (vi) 'Sou sua amiga' ('I am your (female) friend'). In this type of construction, the interpretation of possession, not rarely, the interpretation of possession functions inversely. In fact, the nominal term possessed, at the morphosyntactic level, becomes a possessor term at the discourse level, especially in authoritarian utterances.
\end{abstract}

Keywords: Discourse. Morphosyntax. Possession relation. Authoritarian utterance.

Resumen: Este artículo investiga, por medio de una interfaz entre morfosintaxis y análisis del discurso, la inversión de las relaciones de pose en construcciones del tipo "sou seu x" ['soy su x'], en que x es sustituido por una función social de parentesco o proximidad. Los datos analizados fueron coleccionados desde una metodología específica en portada de búsqueda para observar la ocurrencia de seis construcciones en

* Docente do Programa de Pós-graduação em Letras. ORCID: https://orcid.org/0000-0001-8285-9932. Email:kogawa@unifesp.br.

${ }^{* *}$ Pesquisadora do Laboratório de Investigação em Linguagem e Cognição (LabLinC) - Guarulhos, SP, Brasil. ORCID: https://orcid.org/0000-0002-5277-2008 E-mail: indaia.bassani@unifesp.br. 
contexto de uso: (i) "sou seu marido" ['soy su esposo']; (ii) "sou sua mulher" ['soy su esposa']; (iii) "sou seu pai" [soy su padre']; (iv) "sou sua mãe" ['soy su madre']; (v) "sou seu amigo" ['soy su amigo']; (vi) "sou sua amiga" ['soy su amiga']. En ese tipo de construcción, la interpretación de pose frecuentemente funciona de modo invertido. Efectivamente, el término nominal poseído, en nivel morfosintáctico, se cambia en término poseedor en el discurso, especialmente en decires autoritarios.

Palabras clave: Discurso. Morfosintaxis. Relación de pose. Decir autoritario.

\section{INTRODUÇÃO}

Este artigo empreende uma análise linguístico-discursiva das relações de posse em português brasileiro. O objetivo é demonstrar como a interpretação de algumas construções linguísticas de posse é subvertida no plano discursivo. Essa subversão consiste na inversão de papéis entre termo possuidor e termo possuído no discurso, ou seja, aquilo que se pode prever linguisticamente por meio de relações hierárquicas internamente ao sintagma nominal, no âmbito discursivo desliza para o inesperado e exige a retomada de elementos pré-construídos para entendimento de seu funcionamento.

Com efeito, as construções (i) 'sou seu marido'; (ii) 'sou sua mulher'; (iii) 'sou seu pai'; (iv) 'sou sua mãe'; (v) 'sou seu amigo'; (vi) 'sou sua amiga', quando funcionam como dizeres autoritários, fazem com que a estrutura 'seu/sua $\mathrm{x}$ ' valha como substituto de 'meu/minha y'. Neste sentido, o jogo de imagens (PÊCHEUX, 1997c) implica sempre uma imagem sobrevalorizada de A sobre si mesmo em relação a uma imagem inferiorizada de A sobre B.

Trocando em miúdos, quando A ('marido', 'mulher', 'pai', 'mãe', 'amigo', 'amiga') constrói a relação de posse supramencionada, é para lembrar que B ('mulher', 'marido', 'filho/filha', 'amigo/amiga') deve algo a A e não simplesmente para declarar ou informar que A pertence a B, como levaria a crer a estrutura linguística possessiva tout court.

Sob essa perspectiva, oferecemos ao leitor um texto que procura dar conta de um fenômeno ao mesmo tempo linguístico (a construção da posse em português) e extralinguístico (a relação de posse na singularidade daquilo que falha na ordem linguística). Entendemos, com isso, que o diálogo entre uma linguística intra-sistêmica e uma linguística extra-sistêmica pode ser produtivo na análise dos fenômenos verbais.

\section{ASPECTOS MORFOSSINTÁTICOS DA EXPRESSÃO DE POSSE NAS LÍNGUAS NATURAIS}

Toda língua natural apresenta formas de expressar relações de posse entre entidades, geralmente denotadas por nomes (ou substantivos), dentro de sintagmas nominais (cf. (1) e (3)) ou entre sintagmas nominais alocados em sentenças (cf. (2) e (4)). Entretanto, há variação nos mecanismos morfológicos de que as línguas dispõem para expressar tal relação, além de diferentes graus de especificação semântica do tipo de relação que se estabelece entre os membros envolvidos, questão central deste artigo. 
Como mecanismo de expressão de posse mais geral, a morfologia das línguas indica minimamente a relação entre um sintagma nominal possuidor e um sintagma nominal possuído. Os recursos morfológicos podem variar para expressar essa relação mais básica. Nos exemplos abaixo do português e do inglês, ambas línguas indo-europeias, mas de famílias linguísticas diferentes, observa-se tanto a relação simples de posse expressa pela presença de um pronome possessivo e um substantivo, em que o substantivo é o complemento do pronome (cf. (1) e (3)), quanto a relação simples de posse expressa pela presença de uma preposição que relaciona os sintagmas nominais $A$ mãe/the mother e $o$ aluno/the student em (2) e (4) ou pela partícula denominada possessiva ou genitiva ' $s$ em (5).

No primeiro caso, a relação de posse está marcada pela presença do pronome possessivo e no segundo pela presença da preposição/partícula que relaciona os sintagmas.

(1) Sua mãe.

(2) A mãe do aluno.

(3) Your mother.

3P.POSS. mãe

'Sua mãe'

(4)

The mother of the student

A mãe de o aluno

'A mãe do aluno'

'A mãe do aluno'

The student's mother.

O aluno-PART. mãe.

Esse tipo de expressão pode ser considerado semanticamente simples, pois não revela ramificações de significado no tipo de posse que se estabelece entre os nomes: apenas indica-se que um elemento é o que possui e o outro é o possuído, na concepção gramatical de posse, mas nada na morfologia propriamente revela o tipo de posse que se estabelece entre os termos gramaticais. Segundo Aikhenvald (2019, p. 7), universalmente as relações de posse mais familiares, frequentes e estabelecidas tendem a ser expressas por morfologias menos marcadas, mais curtas e compactas, ao passo que relações menos comuns e mais detalhadas apresentam maior marcação morfológica.

Algumas línguas não indo-europeias podem revelar padrões morfológicos bastante diferentes dos apresentados acima. A língua indígena aweti (tronco Tupi, falada por cerca de 200 falantes em Mato Grosso, Brasil) apresenta um complexo paradigma de expressão de posse por meio de prefixos. Retomando brevemente a descrição apresentada em Monserrat (1976), Borella (2000) e Silva (2018), essa língua dispõe de um sistema de marcação prefixal cujas formas podem variar de acordo com: (i) a fonologia do primeiro segmento da palavra possuída; (ii) o sexo do falante (se a fala é de homem ou de mulher); (iii) o tipo semântico da palavra possuída. Relacionado a esse último fator de variação, tem-se que a relação estabelecida é especificada de acordo com o tipo semântico do elemento possuído, pois os nomes são classificados semântica e morfologicamente em 
duas subcategorias: os nomes possuíveis e os não possuíveis (BORELLA, 2000, p. 65). Os nomes não possuíveis não recebem marcação morfológica e indicam fenômenos da natureza, animais, plantas ou pessoas, como nos exemplos (6) e (7) abaixo.

Os nomes que podem ser possuídos (possuíveis) ocorrem com possuidor expresso por prefixo pronominal e dividem-se em alienáveis e inalienáveis. Os nomes inalienáveis denotam partes de um todo, tais como partes do corpo humano ou de animais, como nos exemplos (8) e (9) e relações de parentesco, como em (7) e (9). Os nomes alienáveis se referem a objetos derivados do mundo cultural, que ocorrem ou não ocorrem com possuidor expresso morfologicamente, mas sempre que são marcados na relação de posse, apresentam também um prefixo pronominal específico denominado relacional (12).

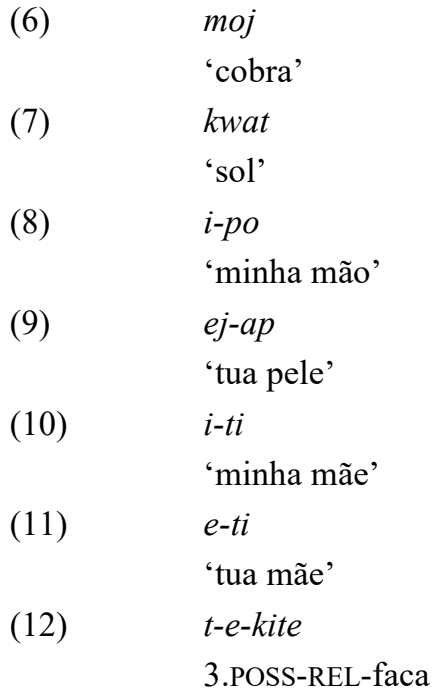

Diante dessa sucinta exposição da diversidade de marcação morfológica da expressão de posse, voltemos ao português brasileiro. Nota-se que, em princípio e diferentemente do que se dá em aweti, a relação de posse não distingue nem semanticamente e nem morfologicamente o tipo de objeto possuído, se objeto do mundo cultural, parentesco ou parte do corpo: nos três dados abaixo, livro, marido e mão são nomes possuídos, o que é expresso pela relação direta com o pronome possessivo de terceira pessoa masculino (seu) ou feminino (sua) ou pela mediação de uma preposição de com os nomes interpretados como possuidores José, Joana, menina, ele, ela ${ }^{1}$.

$$
\begin{aligned}
& \text { Seu livro. } \\
& \text { O livro do José/(d)ele. } \\
& \text { Seu marido. }
\end{aligned}
$$

\footnotetext{
${ }^{1}$ Nesta seção, o conceito de posse utilizado é estritamente gramatical, e se limita a estabelecer a relação entre os dois termos integrantes do sintagma. Por exemplo, em "o livro do José/dele", não se coloca a questão de se "no mundo" o livro era é de outra pessoa e está emprestado ao José. Esse fato extrapola os limites do objeto gramatical. Neste cenário, o elemento gramatical "seu/sua" sempre indica relação de posse/pertencimento. Adiante, a discussão a respeito de posse em nível discursivo, histórico e social será abordada.
} 


$$
\text { O marido da Joana/d(ela). }
$$

\section{Sua mão.}

A mão da menina/(d)ela.

No entanto, nota-se que quando há presença de determinados nomes que expressam relações de parentesco ou hierarquia, sobretudo nomes animados e masculinos, tais como 'pai', 'marido' ou 'chefe', em orações do tipo 'sou seu x', o pronome possessivo de terceira pessoa perde sua função de indicar elemento possuidor e passa a indicar elemento possuído, subvertendo o padrão morfológico da língua. Isso pode se dar de modo mais ambíguo e distenso, como em (19), ou de modo mais intenso e declarado, como em (20):

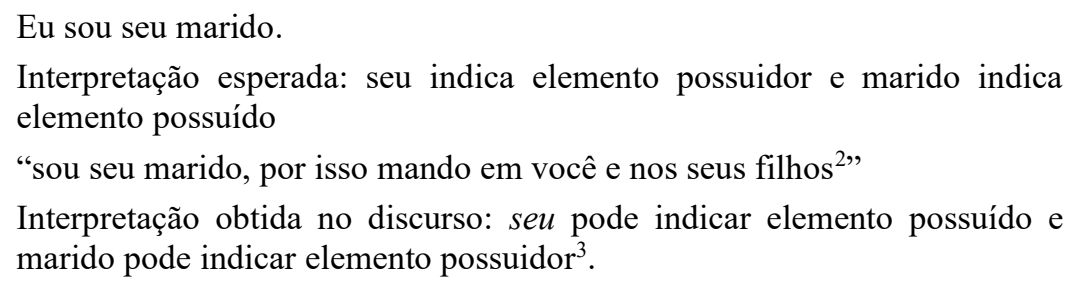

\section{DA OBTENÇÃO DE DADOS QUE DESCONSTROEM A ORDEM LINGUÍSTICA NÃO-MARCADA}

A fala autoritária que inverte as relações de posse na ordem da língua implica o deslocamento do terreno próprio ao sistema para a exterioridade. Com efeito, a necessária observação do comportamento linguístico da relação de posse é condição sine qua non para a materialização da inversão que propomos elucidar. Não há discursividade sem a língua e a língua, por sua vez, está sujeita ao equívoco, ao que foge à sistematicidade.

Nesse sentido, após feita a apreciação sistemática da ideia de posse na língua, com especial enfoque na língua portuguesa, apresentamos o material a partir do qual essa sistematicidade passará por uma inversão relativa à ideia de posse. Para essa análise da exterioridade que inverte a ordem do esperado, procedemos da seguinte forma:

1) Delimitamos um conjunto de seis estruturas sintagmáticas representativas da ideia de posse com potencial de amostragem para o dizer autoritário. São elas: (i) 'sou seu marido'; (ii) 'sou sua mulher'; (iii) 'sou seu pai'; (iv) 'sou sua mãe’; (v) ‘sou seu amigo'; (vi) 'sou sua amiga'.

2) Após essa delimitação, buscamos - digitando cada uma delas - por essas estruturas e suas variantes no site de busca google.com.br.

\footnotetext{
${ }^{2}$ Fonte: https://bit.ly/2LmkX6X. Acesso em: 8 fev. 2019.

${ }^{3}$ Outros casos, incluindo sintagmas possessivos com nomes animados e femininos, serão abordados na seção 4 .
} 
3) Coletamos todas as estruturas encontradas da primeira à décima página do site de buscas mencionado. Os resultados variaram por diferentes tipos de texto: canções, romances, programas televisivos, memes.

4) O tipo de texto não será objeto de discussão, mas o fenômeno de inversão da relação de posse. Nesse sentido, é indiferente para nossa análise se o texto em que a estrutura emergiu é de alto ou baixo status cultural. Interessou para nossa coleta a presença do sintagma.

\section{A RELAÇÃO DE POSSE NA EXTERIORIDADE DA LÍNGUA}

Toda a primeira parte dedicou-se a apontar as organizações morfossintáticas que geram as interpretações canônicas das relações de posse em português - inclusive, por paralelos entre essa e outras línguas - na ordem da língua. Para retomarmos Pêcheux, "[...] esses mecanismos pertencem ao sistema linguístico ou [...] têm a ver com o funcionamento da língua com relação a si mesma" (PÊCHEUX, 1997a, p. 90, grifo do autor). Ainda de acordo com o autor, "[...] todo sistema linguístico, enquanto conjunto de estruturas fonológicas, morfológicas e sintáticas, é dotado de uma autonomia relativa que o submete a leis internas, as quais constituem, precisamente, o objeto da Linguística" (PÊCHEUX, 1997a, p. 91).

Sem negligenciar, portanto, a existência de regras imanentes ao sistema linguístico, o funcionamento das relações de posse na ordem da língua nos instiga a fazer a seguinte questão: em que condições as relações de posse obedecem à estrutura da língua? Haveria aí espaço para o equívoco, para a quebra no horizonte de expectativas?

Em nosso entender, o objeto que agora se apresenta, a saber, construções de posse em que há um deslocamento entre possuído e possuidor no plano discursivo, produz um deslocamento na estrutura pelo efeito da exterioridade. A interpretação da posse, marcada por possessivo de terceira pessoa mais possuído, inverte-se no plano discursivo, apesar de, no plano estritamente linguístico, nada se alterar. Dessa forma, “[...] a Linguística é solicitada constantemente para fora de seu domínio [...]” (PÊCHEUX, 1997a, p. 87, grifo do autor).

Entre a estrutura e o acontecimento (PÊCHEUX, 1997b), a operação de batimento - "[...] a tensão entre descrição e interpretação no interior da análise do discurso" (PÊCHEUX, 1997c, p. 19) - impõe a análise dessa relação entre língua e exterioridade. A estrutura de posse em português, sob esse prisma, para além da existência constatativa de que algo/alguém é possuído por algo/alguém, também serve a construções autoritárias ${ }^{4}$

\footnotetext{
${ }^{4}$ Não empreendemos, por uma questão de delimitação, uma análise sociológica do dizer autoritário. Centrar-nos-emos exclusivamente nas leituras possíveis a partir de dados da língua em funcionamento. Como enfocamos seis construções de tipo autoritário com relação de posse [(i) 'Sou seu marido'; (ii) 'sou sua mulher'; (iii) 'sou seu pai’; (iv) ‘sou sua mãe'; (v) 'sou seu amigo'; (vi) 'sou sua amiga'], uma análise sociológica de cada uma dessas relações demandaria um trabalho à parte. Nesse sentido, a interpretação dos dados linguísticos é suficiente para o nosso objetivo, a saber, analisar a passagem da língua ao discurso que impõe um deslocamento da ordem linguística (o possuído funciona como possuidor) na determinação da posse.
} 
- no plano discursivo - em que possuído/possuidor são deslocados. Em nossas sequências discursivas, o deslocamento do efeito de sentido de posse está no pronome possessivo em sua relação com a posição sujeito possuída. Assim, "Eu sou seu marido", por exemplo, tem uma relação de posse bem marcada na língua. Na leitura linear e estrutural da sequência, "x diz que pertence a alguém". No entanto, no discurso, há um deslocamento da posse: quando um sujeito masculino diz "sou seu marido", nos contextos analisados a seguir, ele não está declarando que pertence ao sujeito feminino, mas impondo que este último deve lhe obedecer. "Sou seu marido", na verdade, é correlato de "Você é minha mulher", prevalecendo, no discurso, este último efeito de sentido de autoritarismo.

Isso se dá quando a pressuposição implica pré-construídos inexistentes na materialidade da posse tout court. Retomando Pêcheux (1997a, p. 99), “[...] o que remete a uma construção anterior, exterior, mas sempre independente, em oposição ao que é ‘construído' pelo enunciado". Tais construções compõem configurações ideológicas aceitas como verdade e reproduzidas na/pela materialidade linguística. Ainda de acordo com Pêcheux, "[...] ao abordar a questão do pré-construído, chegamos a um dos pontos fundamentais da articulação da teoria dos discursos com a Linguística" (PÊCHEUX, 1997a, p. 99, grifo do autor).

Propomos, para este trabalho, uma definição de dizer autoritário sem compromisso com uma teoria sociológica. Sob essa ótica, autoritário deve ser entendido como enunciado a que não se pode contra-argumentar por estar sustentado em evidências de tipo hierárquico advindas de um outro lugar - exterior à língua. No nosso trabalho, especificamente, esse outro lugar é o discurso religioso sustentado na/pela Bíblia. É aí, efetivamente, que as figuras 'marido', 'mulher', 'pai', 'mãe', 'amigo' e 'amiga', são cristalizadas como autoridades. No caso das relações de amizade, isso aparece em grau mais ínfimo. No entanto, há na Bíblia a ideia de que a amizade é imperativa e, como tal, as personagens que compõem essa relação estariam obrigadas a "seguir conselhos" uma da outra. Indiretamente isso implica o "privilégio" ou a necessidade de "dizer ao outro o que se deve fazer", o que pode ser lido não só, mas também, como autoritarismo, conforme demonstramos mais adiante.

Nessa configuração, aquele que fala é sempre construído como autorizado a dizer e aquilo que é dito é posto como verdade a ser seguida e não um ponto de vista a ser debatido. Nesse intuito, retomemos os excertos (19) e (20) dados acima para evidenciar algumas características próprias dos termos que compõem os dois enunciados denotadores de posse na relação com o que propomos denominar dizer autoritário. (i) o elemento possuído não é um nome próprio ou um "objeto do mundo", mas uma função social 'marido' atribuída a um ser animado; (ii) 'seu' é, ao mesmo tempo, um possessivo de terceira pessoa e um demonstrativo; (iii) a condição de 'seu' implica aquilo para o que o pronome aponta, ou seja, o possuidor, que também deverá ser animado; (iv) o efeito de deslocamento se dá no dizer autoritário, no interior do qual o possuído passa a ser o possuidor a partir da sua função social. A materialidade desse discurso pode ser formalizada pela estrutura em (21): 
Quando o nome é tomado como complemento de um pronome possessivo, este deveria ser automaticamente interpretado como elemento possuído, como se observa em 'seu livro'. No entanto, quando o nome é animado e designa função social, produz-se uma inversão da interpretação de posse no dizer autoritário. Da designação de posse esperada passa-se a um desnível hierárquico entre possuidor x possuído enquanto sujeitos.

Em (19), encontramos o significado não-marcado ${ }^{5}$ (PERINI, 2008) da posse, ou seja, o espaço em que a língua prescinde do discurso e as formas cumprem um papel estritamente gramatical. Em si, a sequência 'Eu sou seu marido' não implica o préconstruído de desnível hierárquico. O mesmo vale para as sequências análogas coletadas neste trabalho: (ii) 'sou sua mulher'; (iii) 'sou seu pai'; (iv) 'sou sua mãe'; (v) 'sou seu amigo'; (vi) 'sou sua amiga'.

Isso significa que a relação de posse deslocada na fala autoritária exige a correlação com outros elementos linguísticos do enunciado e nos remete ao jogo de imagens descrito por Pêcheux (1997c, p. 82): "[...] o que funciona nos processos discursivos é uma série de formações imaginárias que designam o lugar que A e B se atribuem cada um a si e ao outro [...]". Assim, temos: (i) a imagem que A faz de A (quem sou eu para lhe falar assim); (ii) a imagem que A faz de B (quem é ele para que eu lhe fale assim); (iii) a imagem que B faz de B (quem sou eu para que me fale assim); (iv) a imagem que B faz de A (quem é ele para que me fale assim). Esses lugares não são derivados da consciência psicológica dos indivíduos, mas do modo como, socialmente, certas posições-sujeito são préconstruídas. Nesse simulacro, parece inadequado pensar em qualquer termo da língua que, preenchendo A ou B, não se refira a posição social, o que reforça nosso argumento de que a subversão das relações de posse só se dá no plano social. Isso não ocorre com seres inanimados.

Observemos o caso de (20): a estrutura básica deveria dizer que 'alguém' possivelmente uma esposa ( $\mathrm{B}$, na cena construída pelo enunciado) - deveria ser, idealmente, dona/possuidora de 'marido' [A, na cena construída pelo enunciado (seu marido $=$ marido dela)]. No entanto, um deslizamento semântico advindo do dizer autoritário ressignifica a estrutura gramatical. O 'marido' (A) gramaticalmente possuído passa a ocupar uma posição-sujeito de possuidor, de autoridade, de mandante, de hierarquicamente superior, apesar de, na materialidade linguística, não ser esse o resultado esperado da combinação das partes. Preenchendo o jogo de imagens de Pêcheux (1997c), teríamos: (i) marido faz de si - apoiado em um discurso autoritário patriarcal que remonta ao texto bíblico, conforme demonstramos adiante - uma imagem de mandatário; (ii) marido faz da mulher uma imagem de submissa. Com relação a B, não temos a resposta configurada no enunciado, mas o autoritarismo aqui se deixa apreender nos dizeres de A e não na resposta de B (seja ela de aceite ou de resistência). Hipoteticamente, a mulher poderia se opor. Isso não inviabiliza a tese de que o enunciado de A é autoritário porque não admite contrapartida argumentativa.

O mesmo ocorre com os seguintes enunciados de nosso corpus (tabela 1 do anexo):

\footnotetext{
${ }^{5} \mathrm{Ou}$ ao menos, ambiguamente marcado, já que 'Eu sou seu marido' não necessariamente implica um dizer autoritário.
} 
(22)

Mulher toma tua linha/Eu sou seu marido ${ }^{6}$.

Sou seu marido agora. Tenho que cuidar da sua reputação. Isso não pega bem para uma mulher casada ${ }^{7}$.

Eduarda eu sou seu marido, eu tenho esse direito ${ }^{8}$.

Quando não concordava com meu marido, ele dizia: 'Você tem de me obedecer, eu sou seu marido's.

Dos quatro itens sistematizados anteriormente, o primeiro - a função social da posição-sujeito - determina a inversão pelo traço "animado" (esse tipo de construção não se dá, como dissemos anteriormente, com objetos inanimados, já que o autoritarismo e a hierarquia inexistem fora de disparidades entre funções sociais). Com efeito, é com vistas à posição-sujeito delimitada pelo naturalizado sócio-historicamente que a falha se aloja na estrutura.

Conforme Pêcheux (1997a, p. 102, grifo do autor) assevera, o pré-construído tem

[...] como uma sua característica essencial, a separação fundamental entre o pensamento e o objeto de pensamento, com a pré-existência deste último, marcada pelo que chamamos uma discrepância entre dois domínios de pensamento, de tal modo que o sujeito encontra um desses domínios como o impensado de seu pensamento, impensado este que, necessariamente, pré-existe ao sujeito.

A pertinência e imprescindibilidade do traço animado - o jogo de imagens de Pêcheux não se aplicaria a relações de posse como nos exemplos (13), (14), (17) e (18) dados anteriormente - no deslocamento da relação de posse pode ser evidenciada por uma rede parafrástica como a elaborada de (26) a (29). Esse argumento pode ser sustentado pelas seguintes paráfrases dos enunciados de de (26) a (29) dadas a seguir:

(26) Cadeira toma tua linha/Eu sou sua mesa.

(27) Sou seu lápis agora. Tenho que cuidar da sua reputação. Isso não pega bem para uma caneta importada.

(28) Cortina eu sou seu trilho. Eu tenho esse direito.

(29) Quando não concordava com minha tábua de passar ela dizia: 'Você tem de me obedecer, sou sua tábua de passar.

Isto é, discursivamente, a relação de posse desloca-se com a condição de que possuidor e possuído não sejam objetos do mundo natural, mas sim, necessariamente, do mundo da história ${ }^{10}$. O pré-construído dos enunciados parafraseados evidencia-se pelo

\footnotetext{
${ }^{6}$ Disponível em: https://bit.ly/2DXZqxn.

${ }^{7}$ Disponível em: https://bit.ly/2sLIc3P.

${ }^{8}$ Disponível em: https://bit.ly/2DKm0t3.

${ }^{9}$ Disponível em: https://bit.ly/2qqI74Q.

${ }^{10}$ Embora seja importante ressaltar essa característica, não voltaremos a isso por considerarmos a questão resolvida do ponto de vista discursivo.
} 
efeito de sentido de verdade assumida de que 'marido' (A) ocuparia uma posição-sujeito mais próxima do possuidor que do possuído. Diante desse cenário, a esposa (B) emerge como lugar de submissão a ser investido de modo incisivo - em alguns casos, até com efeitos de agressividade, como em (22) - por A. Importante enfatizar que, nas construções (22) a (25), nem a suposta neutralidade da estrutura da língua pode alterar isso, pois o que garante a ordem das posições-sujeito na estrutura de posse vem do pré-construído: "Porque o marido é a cabeça da mulher, como também cristo é a cabeça da igreja, sendo ele próprio o salvador do corpo" (Ef. 5:23 $3^{11}$ ).

Isso funciona também quando a relação de posse se dá entre homem e mulher, em que essa guarda mais ou menos a mesma relação como em marido e esposa. Vale destacar que, embora não seja nosso intuito, aqui nos enveredarmos para teorias de tipo sociológico, o gênero importa na forma como o autoritarismo se consolida. Em geral, observamos construções mais incisivas quando a posição-sujeito (A) é masculina. Em contrapartida - ainda que também autoritária -, quando posição-sujeito (A) é feminina, o autoritarismo se dá de modo não incisivo/agressivo, mas por via indireta - sob a forma da vitimização ou chantagem emocional. Cabe esclarecer ainda que a construção (ii) 'sou sua mulher' é a que apresentou dados mais heterogêneos e isso porque, em geral, os valores da sociedade patriarcal brasileira tornam construções autoritárias em que a posição feminina seja a mandatária mais incomum, ao menos se considerarmos a relação marido x mulher/esposa. No entanto, a existência desse tipo de construção denota que a sociedade passou por transformações jurídicas e econômicas e, ainda que seja mais raro, o sujeito feminino também pode assumir uma posição autoritária. Observemos essa heterogeneidade dos dados a partir das quatro amostras que seguem:

Amor, por favor, não desligue o telefone. Eu sou sua mulher e você é o meu homem ${ }^{12}$.

Eu sou sua mulher, sou o maior bem que você vai arrumar nessa vida ${ }^{13}$.

Sou sua mulher, não sua ${ }^{14}$ propriedade $^{15}$.

Não sou SUA mulher! Não tenho dono ${ }^{16}$.

Os enunciados (30) e (31) marcam uma posição autoritária em que A é posiçãosujeito feminina. Nos enunciados (32) e (33), em contrapartida, A deixa de se submeter à autoridade de $\mathrm{B}$ que, pelas marcas linguísticas, pode ser recuperado como tendo reproduzido, anteriormente, um dizer alinhado com o disposto nos enunciados (22) a (25).

\footnotetext{
${ }^{11}$ Disponível em: https://bit.ly/2qn4rwb.

${ }^{12}$ Disponível em: https://bit.ly/2sLIR5j.

13 Disponível em: https://bit.ly/2rTgn9e. Para a cena do filme em que o enunciado aparece, conferir: https://bit.ly/2OR0idl.

${ }^{14}$ Esta segunda ocorrência do pronome não corresponde exatamente às relações que pretendemos enfatizar aqui. Isso porque a desconstrução da posse, na segunda ocorrência, extrapola o funcionamento do pronome pela determinação sofrida pelo advérbio modificador "não". O segundo período apenas apoia o primeiro, restando a este a pertinência para este estudo.

${ }^{15}$ Disponível em: https://bit.ly/2rSM42u.

${ }^{16}$ Disponível em: https://bit.ly/3653Nm9.
} 
Isto é, se nos enunciados em que aparece 'sou seu marido', todos os dizeres marcam o autoritarismo masculino, a ocorrência de 'sou sua mulher' apresenta dados em que, ora a mulher se alinha com o autoritarismo - é autoritária -, ora responde ao autoritarismo masculino nuançando o valor de "sua" em "sua mulher" para, na sequência, negar o que, de forma pré-construída, costuma-se afirmar quando se diz "Você é minha mulher". Assim, a segunda oração de (32), [...] "não sou sua propriedade", é uma paráfrase explicativa para a primeira, em que "sua" poderia, ambiguamente, reforçar $o$ autoritarismo masculino. Parafraseando esta estrutura teríamos algo como: (32a) "Ser sua mulher não significa ser sua propriedade", ou ainda, (32b) "Ei, você, ser sua mulher não lhe dá o direito de fazer isso/ser assim comigo".

No que concerne a (30) e (31), isso se dá mais por manipulação e não tanto por imposição. Um efeito de sentido aí inscrito é o de 'não vá embora', mais enfaticamente sugerido do que uma ideia de 'faça o que eu estou mandando'. Há uma distinção importante a ser observada por retomar um pré-construído sobre a relação de poder entre homem e mulher. Esse pré-construído tem como um dos lugares fundantes o texto bíblico: o já citado versículo 23 do capítulo 5 de Efésios. Além disso, o primeiro teria a seu favor a 'força física'; a segunda, a 'sagacidade'. Há, inclusive, um enunciado prototípico que subverte a ordem do texto bíblico que materializa e valida a sagacidade feminina como arma contra a força masculina: 'O homem é o cabeça do lar/da casa/da família/do relacionamento, mas a mulher é o pescoço ${ }^{17}$,

Assim, o autoritarismo em (30) e (31) não vem da violência incisiva, mas da manipulação gentil e modalizada. A ação demandada é 'não desligar o telefone'. Essa ordem não é dada de modo direto, mas modalizada pelo 'por favor' e reforçada pelo 'sou sua mulher' assim como 'você é o meu homem'. Em (31), isso funciona mais ou menos da mesma forma: dá-se uma ordem indireta pela substituição de uma causa comum tida como 'bem maior' por uma causa individual - da mulher - tida como 'bem maior'. Isso se evidencia se recuperarmos o contexto maior da cena da animação Os incríveis. Nesse quadro mais amplo, precede a fala da mulher descrita em (31) a seguinte fala do marido: 'A parada aqui é um bem maior'. O herói está à procura do uniforme para sair em uma missão de 'salvamento do mundo'. É possível estabelecer uma nuance entre 'bem' e 'bem'. Entre a primeira e a segunda ocorrência, há um efeito de ambiguidade entre 'bem' como 'bondade', 'ação de assistencialismo', antônimo de 'mal' e o 'bem' como 'algo precioso', 'uma joia'.

Em (32) e (33), 'sou sua mulher' é uma resposta ao autoritarismo masculino. Em (32), o enunciado pressupõe um dizer anterior em que um marido teria dito "Você é minha mulher' e, em (33), o enunciado pressupõe um dizer em que o marido teria dito: "sou seu dono" ou algo que equivalha. Isto posto, a relação de posse em 'sou sua mulher' é mais heterogênea, sofrendo inversão no plano discursivo nos enunciados (30) e (31) e mantendo seu significado não-marcado em (32) e (33). É o único caso em nosso material. Contudo, como já afirmamos, nosso objetivo aqui não é uma discussão sociológica a respeito dos papéis "masculino" $\mathrm{x}$ "feminino", mas investigar o deslocamento da relação de posse no discurso. Neste caso, o fator gênero é relevante, mas deixa de sê-lo nos

${ }^{17}$ Disponível, por exemplo, em: https://bit.ly/33Ohh4d. 
seguintes. Se observarmos a relação de parentesco pai x filho e mãe x filho, veremos que o fator gênero sai do primeiro plano. Tanto 'sou seu pai' quanto 'sou sua mãe' submetem a estrutura de posse ao deslocamento no plano discursivo:

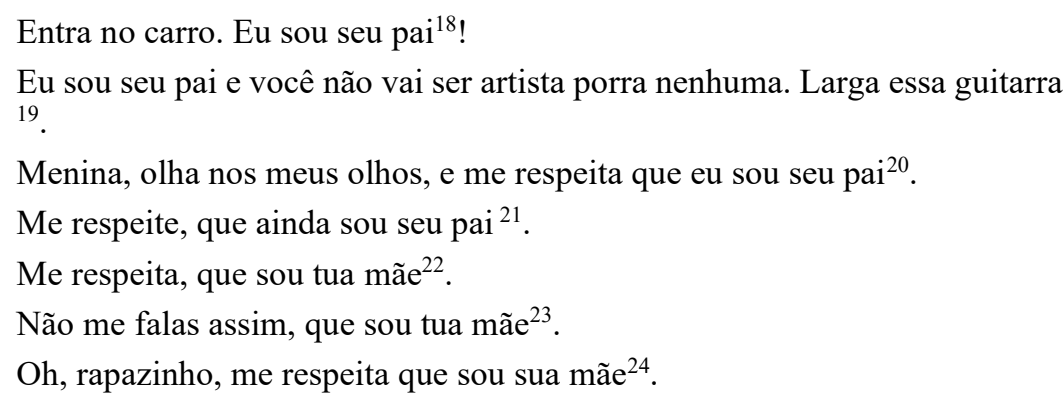

De (34) a (40), 'sou seu pai/sou sua mãe' reproduzem a inversão da posse no nível do discurso, já que não se trata de simplesmente declarar que o filho/filha 'tem um pai e uma mãe', mas de impor uma ordem sem argumento, simplesmente pela retomada do préconstruído segundo o qual filhos devem obedecer seus pais. Se, nos casos atinentes a marido x esposa, o fator gênero associado à posição-sujeito era importante, aqui, é o fator idade associado a paternidade e maternidade o determinante. O pré-construído desses enunciados também encontra sua fundação no texto bíblico: "Honra a teu pai e a tua mãe, para que se prolonguem os teus dias na terra que o senhor teu Deus te dá" (Ex. 20:12 25 ); "Vós, filhos, sede obedientes a vossos pais no Senhor, porque isso é justo. Honra teu pai e a tua mãe, que é o primeiro mandamento com promessa; para que te vá bem, e vivas muito tempo sobre a terra" (Ef. 6:1-3 ${ }^{26}$ ).

Nosso último bloco de enunciados contempla as sequências 'sou seu amigo'/ 'sou sua amiga'.

(41) Depois de dita a frase eu sou seu amigo o humano fica tranquilo e submisso aceitando até ser levado para um passeio ${ }^{27}$.. Shan, me escute. Porque eu sou seu amigo ${ }^{28}$. Porque eu sou sua amiga eu tenho que te dizer: você só fala merda ${ }^{29}$.

\footnotetext{
${ }^{18}$ Disponível em: https://bit.ly/384QVOF.

${ }^{19}$ Disponível em: https://bit.ly/2YgmUXE.

${ }^{20}$ Disponível em: https://bit.ly/35VCTx0.

${ }^{21}$ Disponível em: https://bit.ly/2rQTR0J.

${ }^{22}$ Disponível em: https://bit.ly/2DJN5MP.

${ }^{23}$ Disponível em: https://bit.ly/2DJN5MP.

${ }^{24}$ Disponível em: https://bit.ly/34Qph65.

${ }^{25}$ Disponível em: https://bit.ly/2sElVVo.

${ }^{26}$ Disponível em: https://bit.ly/33P39aL.

${ }^{27}$ Disponível em: https://bit.ly/2Pc22g9.

${ }^{28}$ Disponível em: https://bit.ly/2qpMYmM.

${ }^{29}$ Disponível em: https://bit.ly/386IGBS.
} 
Assim como nos casos anteriores, 'sou seu/sua amigo(a)' funciona de modo a conferir autoridade a A em relação a B. Nesse sentido, mais do que informar que A é amigo de B, o 'seu/sua' invertem a relação de posse, pois, efetivamente, parafraseando os enunciados acima temos, respectivamente:

Sou seu amigo, portanto, vá comigo a um passeio.

Sou seu amigo, portanto, escute-me.

Sou sua amiga e, portanto, te digo: pare de falar merda.

Eu sou sua amiga, portanto, conte-me.

Sob a forma do pedido, da súplica, e da posse na estrutura linguística, A submete B a uma posição de obediência declarada ou velada. Isso se assenta na ideia de que há algo de 'sagrado' na relação de amizade e, mesmo quando o amigo é/está sendo autoritário, isso não é lido dessa forma porque 'é meu amigo/minha amiga quem está falando, portanto, está legitimado'. Esse pré-construído também encontra eco no texto bíblico. Citemos alguns exemplos: "Em todo o tempo ama o amigo e para a hora da angústia nasce o irmão" (Pr. 17:17 $17^{31}$ ); "Leais são as feridas feitas pela amigo, mas os beijos do inimigo são enganosos" (Pr. 27:6 $6^{32}$ ); "Como o ferro com ferro se aguça, assim o homem afia o rosto do seu amigo"(Pr. 27:1733); "Vós sereis meus amigos, se fizerdes o que eu vos mando" (Jo. 15:14 ${ }^{34}$ ).

Sob esse prisma, aqui também a relação de posse encontra-se subvertida, pois aquele que figura linguisticamente como possuidor, no plano discursivo, é 'possuído' e submetido à vontade de A. Assim, 'seu amigo' funciona como substituto de 'meu amigo' do ponto de vista da hierarquização simulada no/pelo discurso. A imagem que A ('seu amigo') faz de si e de B (possuidor de 'sem amigo') é de alguém que deve fazer a vontade de A, assim como observamos nas construções 'sou seu marido/sua mulher' e 'sou seu pai/sua mãe'.

\section{CONCLUSÃO}

A análise de dados reais obtidos por meio de uma metodologia controlada demonstrou que o fenômeno de inversão de posse apresentado neste artigo se dá de modo sistemático e previsível. A partir da descrição da interpretação canônica da posse oriunda das relações morfossintáticas no português brasileiro, exemplificada por possessivo de

\footnotetext{
${ }^{30}$ Disponível em: https://bit.ly/2OTo1tr.

${ }^{31}$ Disponível em: https://bit.ly/2LnqzOa.

${ }^{32}$ Disponível em: https://bit.ly/2req6ac.

${ }^{33}$ Disponível em: https://bit.ly/2OPcfQz.

${ }^{34}$ Disponível em: https://bit.ly/2YeyvXk.
} 
terceira pessoa mais elemento possuído, observa-se a inversão entre possuído e possuidor no plano discursivo quando os nomes envolvidos na formação denotam seres animados que exercem determinadas funções sociais. Observou-se também que o legado bíblico atribuído ao nome inicialmente possuído que passa a possuidor tem papel fundamental na inversão da relação e em seu grau.

O jogo de imagens (PÊCHEUX, 1997c) alimenta-se de pré-construídos assentados especialmente no texto bíblico para retomar valores atinentes às figuras do 'marido', da 'mulher', do 'pai', da 'mãe', do 'amigo' e da 'amiga' - elementos-chave no preenchimento de A e B no simulacro pecheutiano. É desses pré-construídos - [(i) esposa deve obediência ao marido, donde deriva que o marido é o cabeça da família; (ii) se o marido é o cabeça, a mulher é o pescoço; (iii) pai e mãe devem ser obedecidos e honrados sob qualquer circunstância; (iv) amigos são como irmãos] - que emerge a inversão, no plano discursivo, entre possuidor e possuído.

A partir disso, concluímos que a leitura das sequências discursivas está submetida a regras do discurso que impossibilitam a delimitação de uma estrutura para cada efeito de sentido, ou seja, a pluralidade semântica é inerente a uma única configuração linguística sem desambiguização possível do ponto de vista sintático. O diálogo entre morfossintaxe e discurso demonstrou a produtividade do diálogo interdisciplinar (morfossintaxe e semântica discursiva) na descrição da inversão da posse em português em dizeres autoritários.

\section{REFERÊNCIAS}

AIKHENVALD, A. Y. Expressing 'possession': motivations, meanings, and forms. In: JOHANSON, L.; MAZZITELLI, L. F.; NEVSKAYA, I. (Eds.). Possession in Languages of Europe and North and Central Asia. John Benjamins: Expected March 2019. p. 7-25. [Studies in Language Companion Series, 206]

Borella, c. Aspectos morfossintáticos da língua aweti (tupi). 2000. 223f. Dissertação (mestrado em linguística) - programa de pós-graduação em linguística, universidade estadual de campinas, campinas, 2000 .

MONSERRAT, R. M. F. Prefixos pessoais em Aweti. In: Boletim do Museu Nacional Lingüística III. Rio de Janeiro: 1976.

DA SILVA, G. G. Alomorfia em prefixos possessivos da língua aweti. Relatório final de Iniciação Científica. Universidade Federal de São Paulo/FAPESP, 2018.

PÊCHEUX, M. Semântica e discurso: uma crítica à afirmação do óbvio. 3. ed. Tradução de Eni Pulcinelli Orlandi [et al.]. Campinas, SP: Editora da Unicamp, 1997a.

PÊCHEUX, M. O discurso: estrutura ou acontecimento. 2. ed. Tradução de Eni Orlandi. Campinas, SP: Pontes, 1997b.

PÊCHEUX, M. Análise automática do discurso (AAD-69). Tradução de Eni Orlandi. In: GADET, F.; HAK, T. Por uma análise automática do discurso: uma introdução à obra de Michel Pêcheux. Campinas, SP: Pontes, 1997c. p. 61-162.

PÊCHEUX, M. Análise sintática e paráfrase discursiva. In: PÊCHEUX, M. Análise de discurso: Michel Pêcheux. Textos escolhidos e selecionados por Eni Orlandi. Campinas, SP: Pontes, 2011. p. 163-174. PERINI, M. A. Estudos de gramática descritiva: as valências verbais. São Paulo: Parábola, 2008. 


\section{Ocorrências de relações de posse obtidas em busca no google.com.br ${ }^{35}$}

\begin{tabular}{|c|c|c|}
\hline Dado & Fonte (link) & Data da coleta \\
\hline \multicolumn{3}{|l|}{ 'Sou seu marido' } \\
\hline 'sou seu marido, por isso mando em você e nos seus filhos' & https://bit.ly/2rg11f3 & $08 / 02 / 2019$ \\
\hline Mulher toma a sua linha/ Eu sou seu marido & https://bit.ly/2YjeMpi & $08 / 02 / 2019$ \\
\hline $\begin{array}{l}\text { É pena que você pense. Que eu sou seu escravo. Dizendo que eu sou } \\
\text { seu marido. E não posso partir. }\end{array}$ & https://bit.ly/2qo2xeJ & 08/02/2019 \\
\hline $\begin{array}{l}\text { O homem que precisa dizer: Eu sou seu marido e, por isso, você } \\
\text { precisa me obedecer. Está com verdadeiros problemas. }\end{array}$ & https://bit.ly/34OXouZ & 08/02/2019 \\
\hline $\begin{array}{l}\text { Estou aqui porque sou seu marido e essa é nossa noite de núpcias. É } \\
\text { normal compartilhar a cama. }\end{array}$ & https://bit.ly/2PgWHnB & $08 / 02 / 2019$ \\
\hline $\begin{array}{l}\text { Sou seu marido agora. Tenho que cuidar da sua reputação. Isso não } \\
\text { pega bem para uma mulher casada. }\end{array}$ & https://bit.ly/3622yE5 & 08/02/2019 \\
\hline Eduarda eu sou seu marido, eu tenho esse direito & https://bit.ly/34SSiOu & $08 / 02 / 2019$ \\
\hline $\begin{array}{l}\text { Quando não concordava com meu marido, ele dizia: 'Você tem de me } \\
\text { obedecer, eu sou seu marido. }\end{array}$ & https://bit.ly/34PMcOY & 08/02/2019 \\
\hline "Te matei e sou seu marido". & https://glo.bo/2OPIbnZ & $08 / 02 / 2019$ \\
\hline $\begin{array}{l}\text { Mas, como assim? Você sabe que este é o meu trabalho e que a } \\
\text { passarela é a minha vida. - Mas eu sou seu marido e tenho meus } \\
\text { direitos. }\end{array}$ & https://bit.ly/2DQm0HS & 08/02/2019 \\
\hline \multicolumn{3}{|l|}{ 'Sou sua mulher' } \\
\hline Sim sou sua mulher e serei sempre sua namorada & https://bit.ly/3610Y5m & $12 / 02 / 2019$ \\
\hline $\begin{array}{l}\text { Amor, por favor, não desligue o telefone Eu sou sua mulher e você é } \\
\text { o meu homem. }\end{array}$ & https://bit.ly/2RgMHxz & $12 / 02 / 2019$ \\
\hline "Sou sua mulher e vou ser para sempre". & https://bit.ly/360Ylk8 & $12 / 02 / 2019$ \\
\hline $\begin{array}{l}\text { Ontem você me chamou de "minha mulher" e é isso que eu sou: sua } \\
\text { mulher, sua, só sua. E se você quiser que eu seja sua fêmea, eu serei; }\end{array}$ & https://bit.ly/33NqRo1 & $12 / 02 / 2019$ \\
\hline $\begin{array}{l}\text { Eu sou sua mulher, sou o maior bem que você vai arrumar nessa } \\
\text { vida! }\end{array}$ & https://bit.ly/366aB2M & $12 / 02 / 2019$ \\
\hline Sou sua mulher, não sua propriedade. & https://bit.ly/2P7lzOA & $12 / 02 / 2019$ \\
\hline Sou sua mulher, não sua empregada. & https://bit.ly/2OR2AZZ & $12 / 02 / 2019$ \\
\hline sou sua mulher, não sua empregada nem saco de pancadas! & https://bit.ly/354rXNi & $12 / 02 / 2019$ \\
\hline Não sou SUA mulher! Não tenho dono. & https://bit.ly/2OPIlf5 & $12 / 02 / 2019$ \\
\hline \multicolumn{3}{|l|}{ 'Sou seu pai' } \\
\hline Entra no carro EU SOU SEU PAI! & https://bit.ly/38a7eJZ & $12 / 02 / 2019$ \\
\hline $\begin{array}{l}\text { Eu sou seu pai e você não vai ser artista porra nenhuma. Larga essa } \\
\text { guitarra. }\end{array}$ & https://bit.ly/38a60i7 & $12 / 02 / 2019$ \\
\hline 'Menina, olha nos meus olhos, e me respeita que eu sou seu pai!', & https://bit.ly/2qkcv0w & $12 / 02 / 2019$ \\
\hline Me respeite, que ainda sou seu pai. & https://bit.ly/2Pi53LO & $12 / 02 / 2019$ \\
\hline \multicolumn{3}{|l|}{ Sou sua mãe } \\
\hline Eu sou, eu sou, eu sou, eu sou/Porque assim eu sou/A mamãe/A mãe & https://bit.ly/2R14Kmc & $21 / 08 / 2018$ \\
\hline Como faço para as avós perceberem que eu sou a mãe? & https://bit.ly/2YiP30r & $21 / 08 / 2018$ \\
\hline
\end{tabular}

35 Aqui constam todas as ocorrências das sequências estruturadas em 'sou seu x' da primeira à décima página do Google. Nem todas foram utilizadas, portanto, cabe esclarecer que as sequências selecionadas no artigo obedeceram aos seguintes parâmetros: (i) número limitado para ocorrências similares (limitamos ao máximo de quatro sequências para cada caso); (ii) pertinência das sequências ao fenômeno da inversão da posse (ocorrências não muito claras ou de menor relevância constam na tabela, mas não foram utilizadas na análise feita no texto). 


\begin{tabular}{|c|c|c|}
\hline Você me respeite, eu sou sua mãe. & https://bit.ly/2qqMYD6 & $21 / 08 / 2018$ \\
\hline Me respeite, sou sua mãe. & https://bit.ly/2Lpdy6Q & $21 / 08 / 2018$ \\
\hline Mais respeito que sou tua mãe. & https://bit.ly/2rexX7F & $21 / 08 / 2018$ \\
\hline $\begin{array}{l}\text { Há pessoas que estão tentando amar, porque desde o início, a mãe } \\
\text { fíca dizendo à criança, "Você tem que me amar, porque eu sou sua } \\
\text { mãe" }\end{array}$ & https://bit.ly/33LcC2N & $21 / 08 / 2018$ \\
\hline $\begin{array}{l}\text { Ora, filho, eu sou sua mãe. - E eu sou seu filho. Pronto, empatamos. } \\
\text { Agora arrume outra desculpa. }\end{array}$ & https://bit.ly/2RkPkOU & $21 / 08 / 2018$ \\
\hline Eu sou feia, mas sou tua mãe, respeita. & https://bit.ly/2s0Iu6E & $21 / 08 / 2018$ \\
\hline Me respeita que sou tua mãe. & https://bit.ly/2rVVESk & $21 / 08 / 2018$ \\
\hline Mais respeito que sou tua mãe. & https://bit.ly/34P0HCp & $21 / 08 / 2018$ \\
\hline \multicolumn{3}{|l|}{ 'Sou seu amigo' } \\
\hline "Nem precisa me falar essas coisas. Antes de tudo eu sou seu amigo" & https://glo.bo/2ORexP9 & $21 / 08 / 2018$ \\
\hline Eu sou teu amigo há seis anos e tu conhece essa fdp há 6 meses... & https://bit.ly/33L9ggo & $22 / 08 / 2018$ \\
\hline $\begin{array}{l}\text { Depois de dita a frase eu sou seu amigo o humano fica tranquilo e } \\
\text { submisso aceitando até ser levado para um passeio... }\end{array}$ & https://bit.ly/2qrO5T0 & $22 / 08 / 2018$ \\
\hline Não me mata... eu sou seu amigo. & https://bit.ly/2s0NgRC & $22 / 08 / 2018$ \\
\hline $\begin{array}{l}\text { Você sabe porque eu não ti matei até agora. - Porque você é meu } \\
\text { amigo. }\end{array}$ & https://bit.ly/2qp96Ob & $22 / 08 / 2018$ \\
\hline Shan, me escute. Porque eu sou seu amigo. & https://bit.ly/3881V0i & $22 / 08 / 2018$ \\
\hline $\begin{array}{l}\text { Acho que não preciso provar o quanto sou seu amigo na vida, né } \\
\text { cara. }\end{array}$ & https://bit.ly/2LpsdyO & $22 / 08 / 2018$ \\
\hline $\begin{array}{l}\text { Eu sou o tipo de amigo que te ajuda até a esconder um cadáver, mas } \\
\text { se pisar na bola, não se esqueça que eu sei como esconder um } \\
\text { cadáver. }\end{array}$ & https://bit.ly/389aANk & $22 / 08 / 2018$ \\
\hline \multicolumn{3}{|l|}{ 'Sou sua amiga' } \\
\hline $\begin{array}{l}\text { Eu posso não ser a pessoa mais verdadeira, inteligente e sarcástica } \\
\text { que você conhece, mas eu sou e sempre serei a sua melhor amiga. }\end{array}$ & https://bit.ly/3839P8J & $22 / 08 / 2018$ \\
\hline Quando sua amiga saiu sem te chamar: Eu não sou mais sua amiga. & https://bit.ly/2PjuCfL & $22 / 08 / 2018$ \\
\hline Porque eu sou sua amiga eu tenho que te dizer: você só fala merda. & https://bit.ly/2PeuVIC & $22 / 08 / 2018$ \\
\hline $\begin{array}{l}\text { Michele: Por que está chorando? -Lara: Não é nada. Michele: - Eu } \\
\text { sou sua amiga pode me contar. }\end{array}$ & https://bit.ly/2Pev270 & $22 / 08 / 2018$ \\
\hline Eu fui fiel, fui sua amiga/ Você me traiu com as inimigas... & https://bit.ly/367Zg26 & $22 / 08 / 2018$ \\
\hline
\end{tabular}

Eu fui fiel, fui sua amiga/ Você me traiu com as inimigas...

https://bit.ly/367Zg26

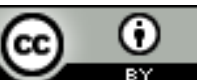

Este texto está licenciado com uma Licença Creative Commons Atribuição 4.0 Internacional. 